
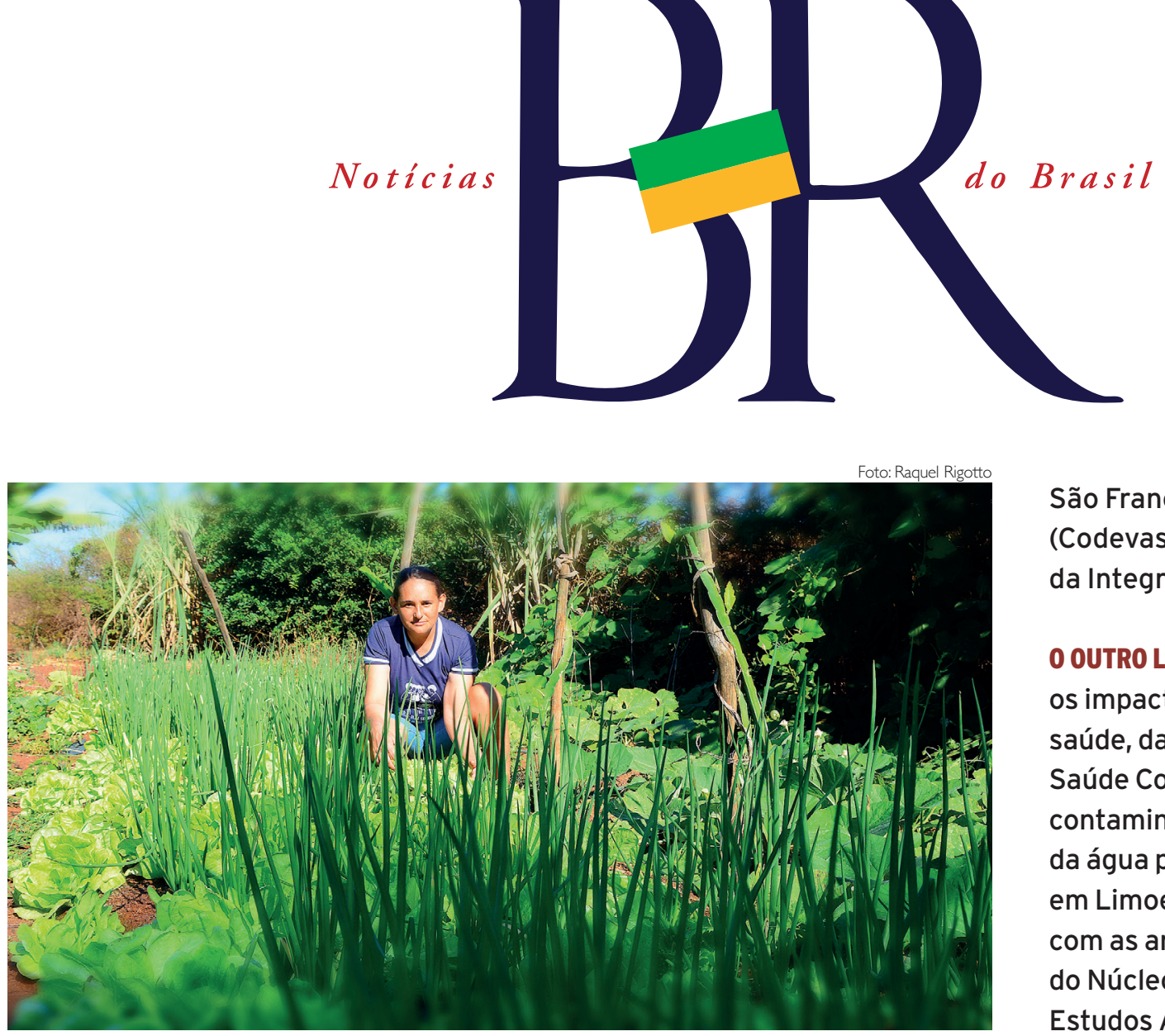

Fruticultura expõe agricultores à contaminação por agrotóxicos

\title{
AGRICULTURA
}

\section{Fruticultura no Nordeste: outras faces da opulência}

Limoeiro do Norte fica a

aproximadamente 209 quilômetros de distância de Fortaleza. Com uma população estimada pelo IBGE em 58 mil habitantes, a cidade integra a microrregião do baixo Jaguaribe, na chapada do Apodi, área que abriga grandes projetos do agronegócio e envolve empresas locais e multinacionais produtoras de frutas para exportação, especialmente banana e abacaxi. Bem-sucedida a produção de frutas colocou o município na lista dos maiores PIBs do Ceará. Desde os anos 1970, o Nordeste tem tido destaque como região produtora em particular os estados do Ceará, de Pernambuco e da Bahia onde investimentos governamentais, disponibilidade de mão de obra barata, irrigação e, claro, uso de agrotóxicos, tem proporcionado aumentos de produção ano após ano. $O$ sucesso no cultivo de manga, melão, uva, mamão, abacaxi e coco tornaram o Brasil o terceiro maior produtor de frutas do planeta, atrás da China e Índia. O caso da região do vale do rio São Francisco é emblemático. A partir dos anos 1970, foi alvo de projetos pioneiros de irrigação e recebeu um grande volume de investimentos da Companhia de Desenvolvimento dos Vales do
São Francisco e do Parnaíba (Codevasp), ligada ao Ministério da Integração Nacional.

0 OUTRO LADO Em 2015, o dossiê sobre os impactos dos agrotóxicos na saúde, da Associação Brasileira de Saúde Coletiva (Abrasco), apontou contaminação por agrotóxicos da água para consumo humano em Limoeiro do Norte. De acordo com as análises do Laboratório do Núcleo Interdisciplinar de Estudos Ambientais Avançados da Universidade Federal de Minas Gerais (UFMG), encomendadas pela Abrasco, a água pode ter sido contaminada pelos agrotóxicos a partir da pulverização e do descarte incorreto de embalagens, ressaltando-se a pulverização aérea, adotada no cultivo da banana e realizada de seis a oito vezes por ano. César Sena, técnico da Câmara Setorial da Fruticultura do Ceará, afirma que aplicação aérea de agrotóxicos é regulamentada por legislação específica, o DecretoLei $n^{\circ} 917 / 1969$, o Decreto ${ }^{\circ}$ $86.765 / 1981$ e as Instruções Normativas do Ministério da Agricultura $n^{\circ} 02 / 2008$ e $n^{\circ}$ 15/2016. “É importante também mencionar a necessidade de atendimento à regulamentação da Agência Nacional de Aviação Civil (Anac), no que for aplicável. A pulverização aérea é muito bem regulada e controlada e, se 
efetuada de acordo com os ditames legais, não provoca contaminação ambiental nem do trabalhador rural", explica.

Depoimentos de agricultores da região, no entanto, contradizem essa afirmação. A agricultora Socorro Guimarães (42), moradora da comunidade do Tomé, em Limoeiro do Norte, conta que a pulverização aérea na região começou entre 2002 e 2003. Segundo ela, os moradores não eram avisados. "Quando a gente cuidava, o avião já estava voando por cima das casas, a comunidade ficava toda cinzenta. Algumas pessoas tinham irritação na pele, espirradeira, dor de cabeça, náuseas", comenta.

\section{VULNERABILIDADES Entre $2006 \mathrm{e}$} 2007, um grupo de pesquisadores traçou um perfil dos trabalhadores rurais empregados na fruticultura irrigada no vale do rio São Francisco. No levantamento, coordenado pela biomédica Cheila Galindo Bedor, da Universidade Federal do Vale do São Francisco (Univasf), em média $12 \%$ deles são analfabetos e $64 \%$ têm apenas o primeiro grau. A baixa escolaridade traz dificuldades para compreender a rotulagem dos agrotóxicos e sua implicação toxicológica e ambiental. "A falta de orientação ocasiona uso em dosagens erradas e aplicação de produtos não específicos", diz. Agrotóxicos do tipo organofosforados são aplicados em média quatro vezes por mês, conforme a cultura. A aplicação é feita por pulverização por trator, costal ou por tração animal, o que acarreta exposição maciça do trabalhador.

Entre os trabalhadores examinados no "Estudo epidemiológico em populações expostas à contaminação ambiental em áreas de uso de agrotóxicos na região Nordeste - NE", realizado entre 2007 e 2010, na região do baixo Jaguaribe, onde fica Limoeiro do Norte, $46,6 \%$ queixaram-se de problemas de saúde, relacionando-os ao uso de agrotóxicos. Na avaliação clínica, $30,7 \%$ apresentaram quadro de provável intoxicação aguda por agrotóxicos. 0 estudo, coordenado pela professora da Faculdade de Medicina da Universidade Federal do Ceará (UFC), Raquel Rigotto, revelou graves falhas no fornecimento e na utilização dos equipamentos de proteção individual (EPIs). Os relatos dos trabalhadores mostraram que era comum o uso de EPIs somente quando havia fiscalização.

Nesse estudo foram entrevistados 540 trabalhadores, divididos em três segmentos: agronegócio, produtores familiares e assentamentos juntamente com comunidades agroecológicas. Os entrevistados dos três segmentos estudados relataram uso de agrotóxico e fertilizantes nos cultivos, sobretudo no ramo do agronegócio $(99,7 \%)$, seguindo-se os agricultores familiares camponeses (97,9\%). No assentamento de reforma agrária, aproximadamente metade dos participantes do estudo não utilizava agrotóxicos e na comunidade em transição agroecológica não havia utilização. Os relatos evidenciaram que havia maior exposição dos trabalhadores em área de pulverização e nas atividades de preparação de misturas, armazenamento e transporte, pulverização costal, descarte de embalagens e limpeza de roupas.

Conforme afirmou Cheila Bedor, "o modelo produtivo atual do agronegócio privilegia o faturamento dessas empresas, deixando em segundo plano as vulnerabilidades das populações expostas aos agrotóxicos. " $\mathrm{Na}$ verdade, o Estado precisa investir mais em tecnologias para reduzir ou eliminar o uso de agrotóxicos. Muitas dessas tecnologias já existem, mas o financiamento, inclusive de pesquisa para manter o modelo atual do agronegócio, é bem maior do que para estudos na área de agroecologia, cujos resultados vêm demostrando há muito que é possível plantar sem o uso dos agrotóxicos", finaliza.

Giselle Soares 